\title{
The Association between Sleep Duration and Overweight in a School-Age Population in Seoul
}

\author{
Sun Mi Shin* \\ Department of Nursing, Joongbu University, Geumsan, Korea
}

Background: This study aimed to investigate the association between body mass index standard deviation scores and sleep duration in a school-age population in Seoul.

Methods: By using the secondary data of a sample survey $(n=25,182)$ of the Student Health Examination in 2010, the proportions of those who were overweight (World Health Organization definition of body mass index $>1.0$ standard deviation score) were identified. The association of overweight with sleep duration was also explored after adjusting for age and for meat and vegetable intake, by using multiple logistic and linear regression analysis.

Results: Only $23.2 \%$ of participants slept 8 hours or more per day. The proportions of overweight participants were $34.2 \%$ of boys and $19.5 \%$ of girls. Significant odds ratios for overweight according to sleep duration (based on $\geq 8$ sleeping hours) were 1.28 (for less than 6 hours), 1.31 (for 6-7 hours), and 1.28 (for 7-8 hours) in boys; and 1.19 (for 6-7 hours) and 1.17 (for 7-8 hours) in girls. Furthermore, significant regression coefficients for standard deviation scores (based on $\geq 8$ sleeping hours) were 0.218 for less than 6 hours, 0.149 for $6-7$ hours, and 0.099 for $7-8$ hours in boys, and $0.137,0.101$, and 0.079 in girls, respectively.

Conclusion: To prevent and manage overweight, it is necessary to develop a school health policy for ensuring optimal sleep duration in school-age population.

Key words: BMI, Overweight, Sleep, School-age population

\author{
Received July 27, 2015 \\ Reviewed August 25, 2015 \\ Accepted February 11, 2016 \\ *Corresponding author \\ Sun Mi Shin \\ (iD) \\ http://orcid.org/0000-0003-4040-6120 \\ Department of Nursing, Joongbu \\ University, 201 Daehak-ro, Chubu- \\ myeon, Geumsan-gun, Chungnam \\ 32713 , Korea \\ Tel: +82-41-750-6255 \\ Fax: +82-41-750-6416 \\ E-mail: healthteam@joongbu.ac.kr
}

\section{INTRODUCTION}

Obesity is increasing in the general population due to easily obtainable high-calorie foods, abundance of products, and decrease in physical activity associated with the use of latest advancements in modern science. Based on data for the 2010 school-age population in the United States, the incidence of obesity within the past 30 years doubled in children and quadrupled in adolescents. In 2012, more than a third of American children and adolescents were either overweight or obese. ${ }^{1}$ Obesity is a state of imbalance caused by excessive caloric intake relative to consumption and results in accumulation of fatty tissue. ${ }^{2,3}$ Obesity tends to influence an individual's behavioral and mental state ${ }^{4}$, causing immediate effects such as a decrease in self-esteem and activity. It is also associated with long-term complications in adults such as vascular disease, diabetes, high blood pressure, and tumors. Risk factors for obesity include family history, diet, exercise, and negative lifestyle habits. Preventive measures with respect to these risk factors are the subject of continued research.

An individual spends one-third of his or her life sleeping. In recent years, there is an increased interest in the length and quality of sleep as obesity-related variables. Sleep not only restores body function and recharges energy for emotional stability, it also plays an important role in various physiological functions such as weight maintenance. ${ }^{5}$ In particular, sleep has an important influence on a child's physical growth as well as emotional/behavioral development. In addition, sleep is closely related to a child's cognitive function, learning, and attention. ${ }^{6,7}$ For example, studies have reported that a child with less sleep has a relatively high hyperactivity-impulsivity score 
and low cognitive performance compared to a child with more sleep. ${ }^{8}$ Moreover, fewer hours of sleep are reported to be related to the obesity and body mass index (BMI) as well as quality of life. ${ }^{9}$

Thus, obesity and sleep are important factors to consider regarding human health and everyday social adjustment. Internationally, studies have been conducted to determine the relationship between obesity and sleep using various stratifications of a population. Compared to international studies, few national studies have been performed to evaluate sleep as a causal variable of obesity. In addition, activities that use sleep time to meet health needs have not yet received significant attention. In this study, the author used the Seoul School Health Examination Standard Survey, which is representative of major metropolitan cities in South Korea, to conduct a research study on the relationship between BMI standard deviation scores (SDS) and sleep time in the elementary to high school population aged between 6 and 18 years.

\section{METHODS}

\section{Research materials and subjects}

A cross-sectional descriptive study was conducted to identify the association of sleep time with overweight World Health Organization (WHO) defined as well as BMI SDS in the Seoul school-age population. This study used the secondary data obtained from the 2010 Seoul School Health Examination Standard Survey that was based on school health examination guidelines. The subjects in this study included 25,797 students in elementary, middle, and high school, who were selected using a random sampling method based on the scale of the population (number of schools, number of classes) and local conditions under consideration. Sex and age-based BMI and BMI SDS were calculated from data for 25,182 subjects aged between 6 and 18 years old, representing 97.6\% of the source population.

\section{Data collection and ethical considerations}

Raw data of the present study were obtained using a School Health Examination procedural policy model for School Health Examination Standard Survey developed by the Ministry of Education, Science, and Technology ${ }^{10}$ to investigate the health state in the school-age population. In the investigation, physical examination included actual measurement of height, weight, vision, and hearing. Health behaviors and symptoms were collected through individual responses to a standardized questionnaire.

Researcher performed an analysis of raw data presented by the Seoul School Health Promotion Center, an institute that analyzes sample surveys for the Seoul School Health examination. At this time, consent was obtained to release and present necessary information for the development of a school health program based on further analysis. Personal identifiers such as place, name, school, class, and numbers were completely removed from the analysis variables, and individual privacy was protected by performing a group rather than an individual analysis.

\section{Measured variables}

From the raw data, variables used in the present study included sex, date of birth, height, weight, meat consumption, vegetable consumption, and sleep time. Using subject dates of birth, individual ages as of June 30th, 2010 were calculated. Those less than 5 years and above 19 years were excluded from the study. BMI $\left(\mathrm{kg} / \mathrm{m}^{2}\right)$ was calculated by measuring the height and weight, and BMI SDS $[(x-\mu) / \sigma]$ for each individual was calculated against average agebased and sex-based BMI values. Those exceeding BMI SDS 1.0 using the sex and age-specific WHO BMI SDS standards ${ }^{11}$ were defined as overweight. As a variable of this study, sleep time was classified into 4 categories, and data were obtained based on the answers to the question, "how many hours do you spend sleeping?": 1) less than 6 hours, 2) 6 to 7 hours, 3) 7 to 8 hours, 4) 8 hours or more. For dietary habits, data on meat and vegetable consumption were collected from the answers to two questions, "how many times per week do you consume meat (beef, pork, chicken, etc.)" and "how many times per week do you consume vegetables (except kimchi)", with the following answer choices: 1) none, 2) 1-2 times, 3) 3-5 times, 4) every day.

\section{Analysis method}

Descriptive statistics and the Chi-square test were used to confirm the proportion of those with WHO-defined overweight in specific age and sex groups. Odds ratios (ORs) for WHO-defined overweight according to specific sleep time were calculated in male and female subjects, using multiple logistic regression analysis that 
controlled for confounding variables of age and consumption of meat and vegetables. Using the same methodology, the influence of sleep time on BMI SDS was analyzed. All analysis was performed with SAS 9.4 (SAS Institute Inc., Cary, NC, USA) and results were presented after excluding missing values for each variable. Statistical significance was reported for $P$-values less than 0.05 .

\section{RESULTS}

\section{Subject characteristics}

Of the 25,182 study subjects, 13,382 (53.1\%) were male and 11,800 (46.9\%) were female students. Subject's ages ranged from 6 to 18 years old. Six-year-old and 18-year-old students comprised $3.8 \%$ and $3.2 \%$ of total subjects, respectively, and they were relatively less represented than other age groups. Weekly intake of meat was reported as none by $4.5 \%$ of subjects and $7.1 \%$ reported daily intake. In addition, $4.2 \%$ reported no weekly consumption of vegetables excluding kimchi, whereas $32.1 \%$ reported daily consumption. Less than 6 hours of sleep was reported by $18.3 \%$ of all students. Eight hours or more 8 hours of sleep was reported by $23.2 \%$ of all students (Table 1).

\section{Proportion with WHO-defined overweight according to sex and age}

Respective BMI values of males and females in different age groups based on the WHO standards were as follows: 17.0, 17.3 in 6-year-olds, 21.7, 22.7 in 13-years-olds, and 24.2, 24.5 in 16-yearolds. The percentages of male and female students classified as overweight were as follows: $33.5 \%$ and $20.6 \%$ of 6-year-olds, $35.7 \%$ and $19.6 \%$ of 13 -year-olds, and $22.5 \%$ and $13.1 \%$ of 16 -year-olds (Table 2).

\section{ORs for overweight according to sleep time}

Using 8 hours or more of sleep time as reference, odds ratios for WHO-defined overweight according to sleep time were analyzed with multiple logistic regression, controlling for confounding factors such as age and meat/vegetable consumption. ORs for sleep time in male students were as follows: 1.28 (95\% confidence interval [CI], 1.11-1.48) with less than 6 hours of sleep, 1.31 (95\% CI, 1.16-1.48) with 6-7 hours of sleep, and 1.28 (95\% CI, 1.15-1.41)
Table 1. General characteristics of subjects, food intake, and sleep duration

\begin{tabular}{|c|c|}
\hline Classification & Subjects \\
\hline \multicolumn{2}{|l|}{ Subjects } \\
\hline Total & 25,182 \\
\hline Male & $13,382(53.1)$ \\
\hline Female & $11,800(46.9)$ \\
\hline \multicolumn{2}{|l|}{ Age } \\
\hline 6 & $956(3.8)$ \\
\hline 7 & $1,814(7.2)$ \\
\hline 8 & 1,961 (7.8) \\
\hline 9 & $1,931(7.7)$ \\
\hline 10 & $1,892(7.5)$ \\
\hline 11 & $1,921(7.6)$ \\
\hline 12 & 2,181 (8.7) \\
\hline 13 & 2,251 (8.9) \\
\hline 14 & 2,354 (9.4) \\
\hline 15 & $2,495(9.9)$ \\
\hline 16 & 2,353 (9.3) \\
\hline 17 & $2,272(9.0)$ \\
\hline 18 & 801 (3.2) \\
\hline \multicolumn{2}{|c|}{ Frequency of meat intake per week } \\
\hline No & $1,119(4.5)$ \\
\hline $1-2$ times & 12,998 (52.3) \\
\hline $3-5$ times & $8,983(36.1)$ \\
\hline Everyday & $1,778(7.1)$ \\
\hline \multicolumn{2}{|c|}{ Frequency of vegetable intake per week (except Kimchi) } \\
\hline No & $1,036(4.2)$ \\
\hline $1-2$ times & $7,250(29.2)$ \\
\hline 3-5 times & $8,592(34.5)$ \\
\hline Everyday & $7,997(32.1)$ \\
\hline \multicolumn{2}{|c|}{ Sleep duration } \\
\hline$<6$ hours & $4,555(18.3)$ \\
\hline $6-7$ hours & $6,947(27.9)$ \\
\hline 7-8 hours & $7,615(30.6)$ \\
\hline$\geq 8$ hours & $5,764(23.2)$ \\
\hline
\end{tabular}

with 7-8 hours of sleep. Differences based on sleep time were found to be statistically significant. ORs in female students were as follows: 1.19 (95\% CI, 1.02-1.39) with 6-7 hours of sleep and 1.17 (95\% CI, 1.03-1.33) with 7-8 hours of sleep (Table 3).

\section{Sleep time-specific regression coefficients for BMI SDS}

The quantitative impact of sleep time on BMI SDS was assessed using regression coefficients in males and females, controlling for age and meat/vegetable intake. In male students, the regression coefficients were $0.218(P<0.0001)$ for less than 6 hours of sleep (compared to the reference of 8 hours or more of sleep), 0.149 
Table 2. BMI Cut-off and proportion of overweight participants according to age and sex

\begin{tabular}{|c|c|c|c|c|}
\hline \multirow[t]{2}{*}{ Classification } & \multicolumn{2}{|c|}{ BMl point of 1.0 SDS } & \multicolumn{2}{|c|}{$\begin{array}{l}\text { Proportion (\%) of } \\
\text { BMl>1.0 SDS* }\end{array}$} \\
\hline & Male & Female & Male & Female \\
\hline Total & & & 34.2 & 19.5 \\
\hline \multicolumn{5}{|l|}{ Age } \\
\hline 6 & 17.0 & 17.3 & 33.5 & 20.6 \\
\hline 7 & 17.4 & 17.7 & 35.6 & 21.5 \\
\hline 8 & 17.9 & 18.3 & 37.5 & 22.4 \\
\hline 9 & 18.4 & 19 & 41.7 & 27.2 \\
\hline 10 & 19.1 & 19.8 & 44.2 & 24.5 \\
\hline 11 & 19.9 & 20.7 & 47.1 & 25.4 \\
\hline 12 & 20.8 & 21.7 & 41.8 & 23.8 \\
\hline 13 & 21.7 & 22.7 & 35.7 & 19.6 \\
\hline 14 & 22.6 & 23.5 & 33.7 & 14.6 \\
\hline 15 & 23.5 & 24.1 & 28.7 & 14.8 \\
\hline 16 & 24.2 & 24.5 & 22.5 & 13.1 \\
\hline 17 & 24.9 & 24.8 & 20.6 & 13.7 \\
\hline 18 & 25.4 & 25 & 19.4 & 11.1 \\
\hline$X^{2}$ & & & 414.51 & 189.70 \\
\hline$P$ value & & & $<0.0001$ & $<0.0001$ \\
\hline
\end{tabular}

*World Health Organization defined overweight as BMI >1.0 standard deviation scores.

$\mathrm{BMI}$, body mass index.

Table 3. Odds ratio of sleep duration for being overweight after adjusting for age and food intake

\begin{tabular}{|c|c|c|}
\hline \multirow{3}{*}{ Classification } & \multicolumn{2}{|c|}{ Overweight* } \\
\hline & Male & Female \\
\hline & OR (95\% Cl) & $\mathrm{OR}(95 \% \mathrm{Cl})$ \\
\hline \multicolumn{3}{|c|}{ Frequency of meat intake per week } \\
\hline No & $1.59(1.28-1.98)$ & $1.27(0.94-1.71)$ \\
\hline $1-2$ times & $1.38(1.19-1.60)$ & $1.36(1.09-1.69)$ \\
\hline 3-5 times & $1.25(1.07-1.45)$ & $1.13(0.90-1.41)$ \\
\hline Everyday & 1.00 & 1.00 \\
\hline \multicolumn{3}{|c|}{$\begin{array}{l}\text { Frequency of vegetable intake per } \\
\text { week (except Kimchi) }\end{array}$} \\
\hline No & $0.84(0.70-1.02)$ & $0.98(0.76-1.26)$ \\
\hline $1-2$ times & $1.00(0.91-1.10)$ & $0.99(0.88-1.12)$ \\
\hline $3-5$ times & $1.05(0.96-1.15)$ & $0.91(0.81-1.02)$ \\
\hline Everyday & 1.00 & 1.00 \\
\hline \multicolumn{3}{|l|}{ Sleep duration } \\
\hline$<6$ hours & $1.28(1.11-1.48)$ & $1.11(0.94-1.33)$ \\
\hline 6-7 hours & $1.31(1.16-1.48)$ & $1.19(1.02-1.39)$ \\
\hline 7-8 hours & $1.28(1.15-1.41)$ & $1.17(1.03-1.33)$ \\
\hline$\geq 8$ hours & 1.00 & 1.00 \\
\hline
\end{tabular}

*WHO defined overweight as $\mathrm{BMI}>1.0$ standard deviation scores.

$\mathrm{OR}$, odds ratio; BMI, body mass index.
Table 4. Effect of sleep duration on BMI SDS for student health examination data using multiple linear regression analysis

\begin{tabular}{|c|c|c|c|c|}
\hline \multirow{3}{*}{ Classification } & \multicolumn{4}{|c|}{ Overweight* } \\
\hline & \multicolumn{2}{|l|}{ Male } & \multicolumn{2}{|l|}{ Female } \\
\hline & Coefficient \pm SE & $P$ value & Coefficient \pm SE & $P$ value \\
\hline Intercept & $-0.041 \pm 0.046$ & 0.370 & $-0.078 \pm 0.051$ & 0.124 \\
\hline Age & $-0.011 \pm 0.003$ & 0.000 & $-0.007 \pm 0.004$ & 0.049 \\
\hline \multicolumn{5}{|c|}{$\begin{array}{l}\text { Frequency of Meat } \\
\text { intake per week }\end{array}$} \\
\hline No & $0.164 \pm 0.051$ & 0.001 & $0.174 \pm 0.055$ & 0.002 \\
\hline $1-2$ times & $0.078 \pm 0.032$ & 0.014 & $0.128 \pm 0.037$ & 0.002 \\
\hline 3-5 times & $0.050 \pm 0.032$ & 0.119 & $0.065 \pm 0.038$ & 0.087 \\
\hline Everyday & Ref & & Ref & \\
\hline \multicolumn{5}{|c|}{$\begin{array}{l}\text { Frequency of vegetable } \\
\text { intake per week } \\
\text { (except Kimchi) }\end{array}$} \\
\hline No & $-0.114 \pm 0.043$ & 0.008 & $-0.039 \pm 0.051$ & 0.441 \\
\hline $1-2$ times & $0.009 \pm 0.022$ & 0.687 & $-0.010 \pm 0.024$ & 0.677 \\
\hline 3-5 times & $0.029 \pm 0.021$ & 0.171 & $-0.029 \pm 0.022$ & 0.200 \\
\hline Everyday & Ref & & Ref & \\
\hline \multicolumn{5}{|l|}{ Sleep duration } \\
\hline$<6$ hours & $0.218 \pm 0.033$ & $<0.0001$ & $0.137 \pm 0.035$ & $<0.0001$ \\
\hline 6-7 hours & $0.149 \pm 0.028$ & $<0.0001$ & $0.101 \pm 0.031$ & 0.001 \\
\hline 7-8 hours & $0.099 \pm 0.024$ & $<0.0001$ & $0.079 \pm 0.027$ & 0.003 \\
\hline$\geq 8$ hours & Ref & & Ref & \\
\hline
\end{tabular}

* World Health Organization defined overweight as BMI >1.0 standard deviation scores.

$\mathrm{BMI}$, body mass index; $\mathrm{SE}$, standard error.

$(P<0.0001)$ for 6-7 hours of sleep, and $0.099(P<0.0001)$ for 7-8 hours of sleep. In female students, regression coefficients were 0.137 $(P<0.0001)$ for less than 6 hours of sleep (compared to the reference of 8 hours or more of sleep), $0.101(P<0.001)$ for 6-7 hours of sleep, and $0.079(P<0.01)$ for 7-8 hours of sleep (Table 4$)$.

\section{DISCUSSION}

Human health is not only influenced by genetics, but also by health behaviors. In addition, specific health risk behaviors are reinforced by various social and environmental factors. Individuals are under pressure from having to adapt to ever-changing systems because of excessive competition, and try to achieve better performance than others by reducing the time spent sleeping. Especially in Korea, it is expected that school-age students will reduce sleep time to achieve more in school and that adolescents will reduce sleep time to develop habits that ensure a successful future. 
In today's society characterized by abundance, obesity is considered an individual health problem that should be prevented and even as a disease that should be treated. Attempts are being made to identify new factors related to obesity, other than those that are already well known, including eating habits, exercise, and genetic factors. Recently, there has been an increased interest in sleep time as a factor related to obesity.

In this study, only $23.2 \%$ of students had 8 hours or more of sleep time. Lack of sleep results in imbalance of hormones that control appetite and energy use, which subsequently increases the risk of obesity. ${ }^{12,13}$ Studies on obesity and sleep have been conducted among adult populations, and the results have repeatedly shown a negative correlation between the two factors. ${ }^{14-16}$ Studies in middle school and high school students in Korea have demonstrated that increased sleep time may reduce the risk of being overweight or obese. ${ }^{17}$ However, these studies excluded elementary school students, which makes it difficult to assess the entire population of students. Moreover, studies assessing the influence of sleep using the standard value of BMI SDS have been limited. Thus, this study was conducted among elementary, middle, and high school students in Seoul, a major metropolitan city in Korea, to analyze odds ratios for sleep time-specific WHO-defined overweight and regression coefficients for BMI SDS.

Theoretically, BMI SDS 1.0 corresponds to $84.1 \%$ of the standard distribution. ${ }^{18}$ The present study defined values more than BMI SDS 1.0 as overweight, consistent with the WHO definition. ${ }^{11}$ As a result, the proportion with overweight in males and females was $33.5 \%$ and $20.6 \%$ among 6-year-olds, $35.7 \%$ and $19.6 \%$ among 13 -year-olds, and $22.5 \%$ and $13.1 \%$ among 16 -year-olds. Overall, the rate of overweight was higher in males. This result was in agreement with previous research conducted in middle and high school students showing that there is a higher frequency of overweight obesity in boys than in girls. ${ }^{19}$ However, a different interpretation is required because of conflicting results presented by previous studies, showing that $\mathrm{BMI}$ is higher in girls than in boys and that a higher age-based increase in BMI occurs in girls compared to boys. ${ }^{20}$

Shorter sleep time is associated with a higher frequency of WHO-defined overweight. In males, ORs for each sleep time, with a reference sleep time of 8 hours or more, calculated after controlling for variables such as age and meat/vegetable consumption were as follows: 1.28 (95\% CI, 1.11-1.48) for sleep time less than 6 hours, 1.31 (95\% CI, 1.16-1.48) for 6-7 hours of sleep, and 1.28 (95\% CI, 1.15-1.41) for 7-8 hours of sleep. In females, the values were 1.19 (95\% CI, 1.02-1.39) for 6-7 hours of sleep time and 1.17 (95\% CI, 1.03-1.33) for 7-8 hours of sleep time. These results were similar in males.

Sleep time had a negative correlation with quantitative BMI SDS values. Respective regression coefficients for BMI SDS in males and females after controlling for age and meat/vegetable intake were $0.218(P<0.0001)$ and $0.137(P<0.0001)$ in those with less than 6 hours of sleep compared to the reference of those with 8 hours or more of sleep, $0.149(P<0.0001)$ and $0.101(P<0.005)$ in those with 6-7 hours of sleep, and $0.099(P<0.0001)$, and $0.079(P<$ $0.005)$ in those with 7-8 hours of sleep. The slope of regression coefficients for BMI SDS increased with a decrease in sleep time.

In the present study, meat intake as a confounding variable had an association with WHO-defined overweight and BMI SDS. Especially in males, the OR for overweight with no intake of meat compared to daily intake of meat was 1.59 (95\% CI, 1.28-1.98), and the regression coefficient for BMI SDS was $0.164(P<0.005)$. In females, the OR for overweight with once or twice weekly intake of meat compared to daily intake was 1.36 (95\% CI, 1.09-1.69), and the regression coefficient for BMI SDS was $0.128(P<0.005)$. This result indicates that intake of lean, low-calorie meat is relatively good and may have a positive influence on prevention of overweight. Therefore, adequate protein intake is emphasized for the prevention and management of overweight.

In males, the regression coefficient for BMI SDS with irregular intake of vegetables compared to daily intake of vegetables was low at $-0.114(P<0.01)$. This result conflicts with the report that BMI increases with high-protein, low-fiber diets, and that vegetarians have lower BMI values than carnivores. ${ }^{21,22}$

In females, the regression coefficient was low with irregular intake of vegetables compared with that for daily intake, but this was not statistically significant. The difference between these findings is due to the fact that this is a cross-sectional study and it was not possible to completely control the confounding variables associated with BMI. Overweight studies that consider Korea's economy (meat is more expensive than vegetables), as well as the possibility of inadequate protein intake in vegetarians, should be performed. 
The limitations of the present study are as follows. First, the purpose of this study is to identify the proportion with WHO-defined overweight based on BMI SDS. For this information, it would be ideal to have standard values for Korean children and adolescents. However, the 2007 Korea Pediatrics Growth Chart ${ }^{23}$ presents the BMI value as a percentile instead of BMI SDS. The present study utilized growth reference values for 5-19-year-olds reported by WHO. ${ }^{11}$ Thus, this study is limited in that a direct comparison to a standard for Korean adolescents is not available.

Second, this study used the school-age population in Seoul, which makes it difficult to generalize the results to the school-age population in Korea. Nevertheless, the school-age population in Seoul comprises $20 \%$ of Korea's school-age population. Thus, it is possible to derive some significance by determining the relationship between overweight and sleep habits of the school-age population in Seoul.

Third, there may be differences in sleep time based on age groups in Korea's educational environment. However, sleep time is an interval variable in this study. Age group-specific sleep time was not under consideration, and analysis was performed against a group with 8 or more hours of sleep. In this case, recommending the importance of adequate sleep time can be ambiguous. However, in 2015, the National Sleep Foundation recommended 9-11 hours of sleep in 6-13-year-olds and 8-10 hours of sleep in 14-17-yearolds. ${ }^{24}$ Thus, using a threshold of 8 hours or more of sleep in middle or high school in Korea may be reasonable.

Fourth, the data used in this study included variables known to be associated with overweight such as exercise and career-related stress factors. However, responses regarding these items on the survey questionnaire used in elementary, middle, and high schools showed discrepancies, which prevented the use of these variables as confounding factors. This could limit the explanation of the relationship between sleep time and the state of being overweight. Nevertheless, this can still partially provide evidence for the need to emphasize the importance of sleep time in management policies for school-age overweight and strategies for school health promotion.

In addition, this study used actual measurements of height and weight with a standardized measuring tool and method to calculate BMI. Therefore, over- or underreported values are less likely, which can be considered a strength of this study.
In conclusion, sleep time is independently related to WHO-defined overweight and BMI SDS after controlling for confounding factors. However, only $23.2 \%$ of students sleep for 8 hours or more. Therefore, health policies encouraging and ensuring adequate sleep in the youth should be actively established. Further studies are needed to the association of meat intake with BMI SDS as well as WHOdefined overweight reported in male population.

\section{CONFLICTS OF INTEREST}

There is no conflict of interest.

\section{ACKNOWLEDGMENTS}

I would like to thank the Seoul School Health Promotion Center and Hee Woo Lee, M.D. (former provincial, fourth grade official) for their permission to use data and conduct this study.

\section{REFERENCES}

1. Ogden CL, Carroll MD, Kit BK, Flegal KM. Prevalence of childhood and adult obesity in the United States, 2011-2012. JAMA 2014;311:806-14.

2. Daniels SR, Arnett DK, Eckel RH, Gidding SS, Hayman LL, Kumanyika S, et al. Overweight in children and adolescents: pathophysiology, consequences, prevention, and treatment. Circulation 2005;111:1999-2012.

3. Krebs NF, Himes JH, Jacobson D, Nicklas TA, Guilday P, Styne D. Assessment of child and adolescent overweight and obesity. Pediatrics 2007;120 Suppl 4:S193-228.

4. Must A, Jacques PF, Dallal GE, Bajema CJ, Dietz WH. Longterm morbidity and mortality of overweight adolescents. a follow-up of the Harvard Growth Study of 1922 to 1935. N Engl J Med 1992;327:1350-5.

5. Lumeng JC, Somashekar D, Appugliese D, Kaciroti N, Corwyn RF, Bradley RH. Shorter sleep duration is associated with increased risk for being overweight at ages 9 to 12 years. Pediatrics 2007;120:1020-9.

6. Anders TF, Eiben LA. Pediatric sleep disorders: a review of the past 10 years. J Am Acad Child Adolesc Psychiatry 1997; 
36:9-20.

7. Sadeh A, Gruber R, Raviv A. The effects of sleep restriction and extension on school-age children: what a difference an hour makes. Child Dev 2003;74:444-55.

8. Touchette E, Petit D, Tremblay RE, Boivin M, Falissard B, Genolini C, et al. Associations between sleep duration patterns and overweight/obesity at age 6. Sleep 2008;31:1507-14.

9. Gangwisch JE, Malaspina D, Boden-Albala B, Heymsfield SB. Inadequate sleep as a risk factor for obesity: analyses of the NHANES I. Sleep 2005;28:1289-96.

10. The ministry of Education's manual of school health examination standard survey, 2009-2011. Seoul: The ministry of Education; 2009. Introduction of survey; p. 1-9.

11. World Health Organization. Growth reference 5-19 years. [online] 2015 [accessed 2016 Jan 18]; Available from: URL: http:// www.who.int/growthref/who2007_bmi_for_age/en/

12. Spiegel K, Tasali E, Penev P, Van Cauter E. Brief communication: Sleep curtailment in healthy young men is associated with decreased leptin levels, elevated ghrelin levels, and increased hunger and appetite. Ann Intern Med 2004;141:846-50.

13. Seicean A, Redline S, Seicean S, Kirchner HL, Gao Y, Sekine M, et al. Association between short sleeping hours and overweight in adolescents: results from a US Suburban High School survey. Sleep Breath 2007;11:285-93.

14. Kripke DF, Garfinkel L, Wingard DL, Klauber MR, Marler MR. Mortality associated with sleep duration and insomnia. Arch Gen Psychiatry 2002;59:131-6.

15. Gupta NK, Mueller WH, Chan W, Meininger JC. Is obesity associated with poor sleep quality in adolescents? Am J Hum Biol 2002;14:762-8.

16. Kohatsu ND, Tsai R, Young T, Vangilder R, Burmeister LF,
Stromquist AM, et al. Sleep duration and body mass index in a rural population. Arch Intern Med 2006;166:1701-5.

17. Park S. Association between short sleep duration and obesity among South Korean adolescents. West J Nurs Res 2011;33: 207-23.

18. Preedy VR, editors. Handbook of anthropometry: physical measures of human form in health and disease. New York: Springer Science Business Media; 2012. p. 1-3107.

19. Lee B. Association between sleep duration and body mass index among South Korean adolescents. Korean J Health Promot 2015;15:16-23.

20. Sweeting H, West P. Gender differences in weight related concerns in early to late adolescence. J Epidemiol Community Health 2002;56:700-1.

21. Spencer EA, Appleby PN, Davey GK, Key TJ. Diet and body mass index in 38000 EPIC-Oxford meat-eaters, fish-eaters, vegetarians and vegans. Int J Obes Relat Metab Disord 2003; 27:728-34.

22. Burkert NT, Muckenhuber J, Großschädl F, Rásky E, Freidl W. Nutrition and health - the association between eating behavior and various health parameters: a matched sample study. PLoS One 2014;9:e88278.

23. Moon JS, Lee SY, Nam CM, Choi JM, Choe BK, Seo JW, et al. 2007 Korean National Growth Charts: review of developmental process and an outlook. Korean J Pediatr 2008;51:1-25.

24. National Sleep Foundation. National sleep foundation recommends new sleep times. [serial online] 2015 Oct [accessed 2015 Oct 15]; Available from: URL: https://sleepfoundation. org/media-center/press-release/national-sleep-foundation-recommends-new-sleep-times 